\title{
Fluorescence Study of Dehydroabietic Acid-Based Bipolar Arylamine-Quinoxalines
}

\author{
H. D. Burrows, ${ }^{1,3}$ S. M. Fonseca, ${ }^{1}$ B. Gigante, ${ }^{2}$ M. A. Esteves, ${ }^{2}$ and A. M. Guerreiro ${ }^{2}$ \\ Received October 31, 2005; accepted December 5, 2005 \\ Published online: February 10, 2006
}

\begin{abstract}
The absorption and fluorescence spectra, lifetimes and quantum yields of a series of triarylaminequinoxaline bipolar compounds, with and without the bulky dehydroabietic acid group, have been studied in toluene solution. This bulky group is introduced to improve solubility and thermal properties of these systems. It is shown that this does not affect their spectral or photophysical behavior. The compounds show relatively strong fluorescence, with the emission maximum strongly dependent upon the substituents present. Oxidation potentials have also been determined in acetonitrile solution, and again indicate that introduction of the resin acid moiety has no effect on these properties.
\end{abstract}

KEY WORDS: Fluorescence; triarylamines; quinoxalines; dehydroabietic acid.

\section{INTRODUCTION}

The area of molecular electronics has developed to the state of maturity where organic and polymeric semiconductor systems are now finding commercial applications, and are being intensively studied for use in areas such as light-emitting diodes (LEDs), thin film transistors and photovoltaic systems [1,2]. For many of these applications, efficiency is increased dramatically in the presence of charge-transporting molecules, such as aromatic amines for holes [3] and quinoxalines for electrons [4,5]. There is also considerable interest in the use of bipolar molecules in these devices, where both electron and holetransporting groups are present [4-6]. For applications in LEDs, knowledge of the photophysical characteristics of the charge-transporting materials are fundamental for optimizing device properties, and are also valuable for the design of potential new blue-light emitters. In addition, the processability of molecules for these applica-

\footnotetext{
${ }^{1}$ Departamento de Química, Universidade de Coimbra, 3004-535 Coimbra, Portugal.

${ }^{2}$ INETI-DTIQ, Estrada do Paço do Lumiar, 22, 1649-038 Lisbon, Portugal.

${ }^{3}$ To whom correspondence should be addressed. E-mail: burrows@ ci.uc.pt.
}

tions is an important property. Solvent-based methods, such as spin coating, have proved particularly attractive for preparing thin film devices. However, these require both high solubility in volatile solvents and compounds which do not crystallise readily. We have recently shown that triarylamines with a resin acid moiety have excellent solubility and film-forming properties which make them good candidates as hole transport layers [7,8]. We extend this study to dehydroabietic acid-based triarylaminequinoxaline bipolar compounds with potential for device applications. Introduction of bulky groups into aromatic amines can affect both the spectra and photophysics of these compounds [9]. We have therefore compared their behavior with the corresponding compounds without this group, and report a study of their fluorescence behavior in toluene solution.

\section{EXPERIMENTAL}

\section{Materials}

The structures of a series of bipolar compounds featuring dehydroabietic acid-based quinoxalines acceptors fused to various triarylamine donors (1-4) and the analogues (5-8) used in this study are given in Fig. 1. They have been synthesized following a two-step procedure as 


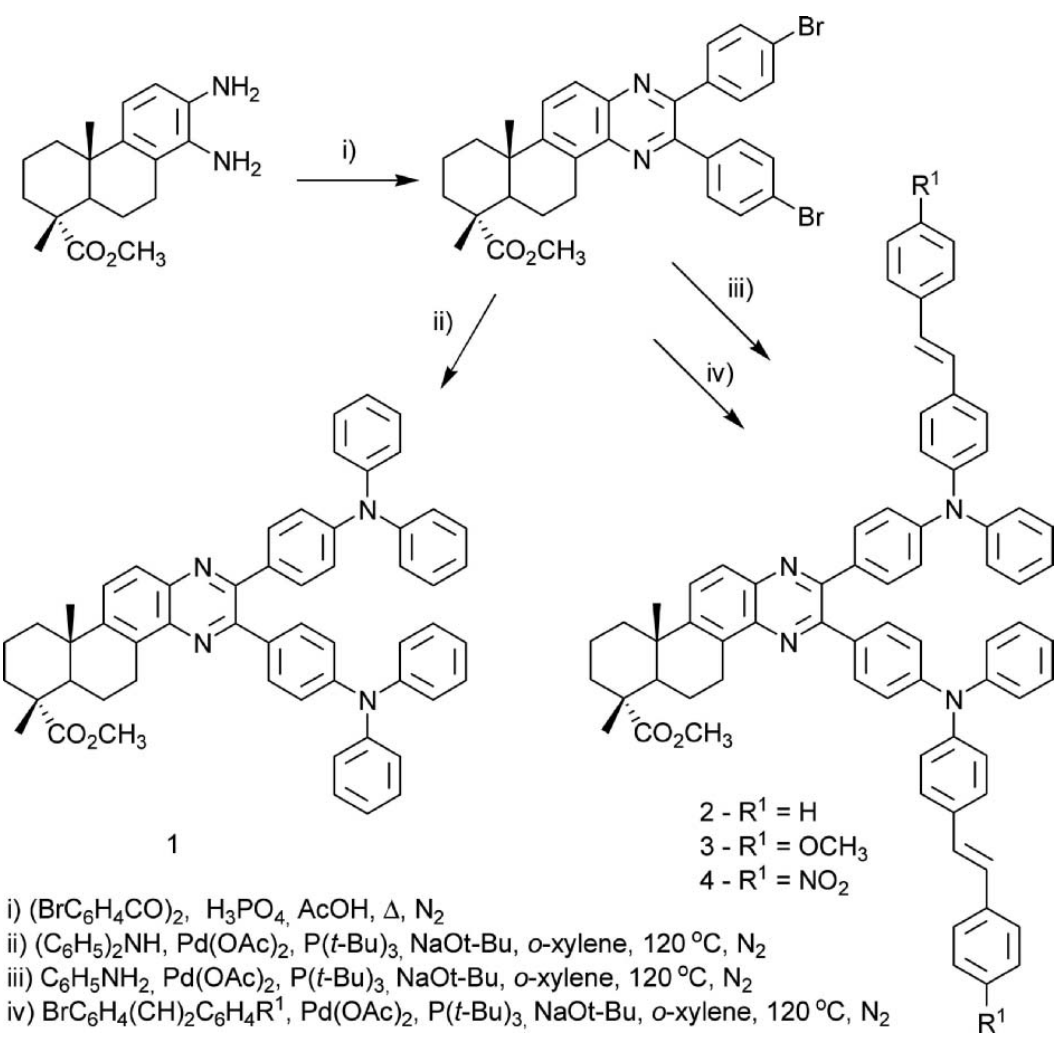

Scheme 1.

depicted for (1-4) in Scheme 1. Thus, by a mild acid catalyzed condensation of two ortho-anilines, respectively, methyl 13,14-diaminodeisopropyldehydroabietate [10] or commercially available 1,2-diaminobenzene with dibromobenzil, the dibromoquinoxaline intermediates were prepared, which by reaction with different diarylamines gave the compounds (1-4) and (5-8). The amination reaction takes place rapidly by using the catalyst combination of $\mathrm{Pd}(\mathrm{OAc})_{2}$ and a bulky and electron-rich phosphine, $\mathrm{P}(\mathrm{t}-$ $\mathrm{Bu})_{3}$ [11]. The intermediates and the bipolar compounds (1-4) and (5-8) were purified by repeated recrystallization or column chromatography. Details of the synthesis and characterization will be given later [12].

\section{Methods}

Absorption and fluorescence spectra were recorded on a Shimadzu UV-2100 and a Jobin-Yvon SPEX Fluorolog 3-22 spectrometer, respectively. All the fluorescence spectra were corrected for the wavelength response of the system. Fluorescence quantum yields were measured using tetrathiophene $\left(\phi_{\mathrm{F}}=0.18\right.$ in benzene) and pentathiophene $\left(\phi_{\mathrm{F}}=0.34\right.$ in benzene $)$ as standards
[13]. Fluorescence decays were measured using a homebuilt time-correlated single photon counting (TCSPC) apparatus with a Horiba-JY-IBH nanoLED (373 nm) as excitation source, Jobin-Yvon monochromators, Philips XP2020Q photomultiplier, and Canberra instruments TAC and MCA. The fluorescence decays were analyzed employing the method of modulating functions [14]. Oxidation potentials were determined by cyclic voltammetry using an EG\&G Princeton Applied Research Potentiostat Model 273A. A three-electrode system was used, with a platinum counter electrode, a platinum working electrode, and a $\mathrm{KCl}$ saturated calomel reference electrode (SCE). Tetrabutylammonium hexafluorophosphate was used as the supporting electrolyte. The electrochemical properties were determined in acetonitrile and all the other photophysical parameters were determined in toluene.

\section{RESULTS AND DISCUSSION}

The absorption spectra of dehydroabietic acid-based quinoxalines acceptors fused to various triarylamine donors (1-4) and their analogues (5-8) show strong 
<smiles></smiles>

$1-\mathrm{R}=\mathrm{H}$
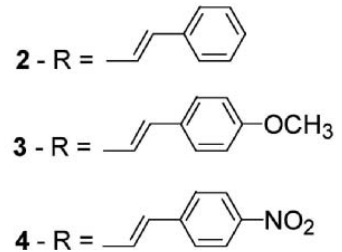<smiles>[R]c1ccc(N(c2ccccc2)c2ccc(-c3nc4ccccc4nc3-c3ccc(N(c4ccccc4)c4ccc([R])cc4)cc3)cc2)cc1</smiles>

$5-\mathrm{R}=\mathrm{H}$<smiles>[B]C#CC=Cc1ccccc1</smiles><smiles>[Z7][R]#CC=Cc1ccc(OC)cc1</smiles><smiles>[B]C=CC=Cc1ccc([N+](=O)[O-])cc1</smiles>

Fig. 1. Structures of a series of bipolar compounds featuring dehydroabietic acid-based quinoxalines acceptors fused to various triarylamine donors (1-4) and their analogues (5-8).

absorption bands and their maximum absorption wavelengths are shown in Table I. As examples, the absorption spectra for compounds $\mathbf{1}$ and $\mathbf{4}$ are given in Figs. 2 and 3, respectively. It can be seen that the absorption maxima can be tuned significantly by changing the substituents on the arylamine rings, but it is not affected by the presence of the dehydroabietic acid moiety. The molar extinction coefficients $(\varepsilon)$ were obtained with five solutions of different concentrations. Good Beer-Lambert plots were obtained in all cases, and the slope of the plot of the absorption values (at the maximum wavelength of absorption) vs. the concentration values gives us the $\varepsilon$ values shown in Table I.
The fluorescence spectra for compounds $\mathbf{1}$ and $\mathbf{4}$ are shown in Figs. 2 and 3, respectively. As can be seen in Table I, the emission maxima can also be tuned over a wide range by changing the substituents on the arylamine rings, while the presence of the dehydroabietic acid moiety slightly shifts the emission maxima towards longer wavelengths $(10-17 \mathrm{~nm})$ with the exception of compound 8. There is no significant correlation between spectral data and oxidation potentials, suggesting that the triarylamine group only plays a relatively minor role in the lowest energy excited state. For compound $\mathbf{5}$, the absorption and emission properties are similar to literature data for this compound [6], except for a somewhat lower value for

Table I. Electrochemical and Photophysical Properties of a Series of Bipolar Compounds Featuring Dehydroabietic Acid-Based Quinoxalines Acceptors Fused to Various Triarylamine Donors (1-4) and Their Analogues (5-8)

\begin{tabular}{|c|c|c|c|c|c|c|c|}
\hline Cpd & $E_{\mathrm{ox}}(\mathrm{V})^{\mathrm{a}}$ & $\lambda_{\text {abs }}(\mathrm{nm})$ & $\varepsilon_{\max }\left(\mathrm{M}^{-1} \mathrm{~cm}^{-1}\right)$ & $\lambda_{\mathrm{em}}(\mathrm{nm})$ & $\phi_{\mathrm{F}}$ & $\tau_{\mathrm{F}}(\mathrm{ns})$ & $k_{\mathrm{F}}\left(10^{9} \mathrm{~s}^{-1}\right)$ \\
\hline 1 & 1.03 & 400 & 26786 & 465 & 0.315 & 1.80 & 0.175 \\
\hline 5 & 1.05 & 403 & 25746 & 475 & 0.334 & 2.20 & 0.152 \\
\hline 2 & 0.83 & 368 & 39102 & 472 & 0.350 & 2.07 & 0.169 \\
\hline 6 & 0.84 & 368 & 75085 & 487 & 0.348 & 2.69 & 0.129 \\
\hline 3 & 0.84 & 367 & 97057 & 480 & 0.344 & 2.41 & 0.143 \\
\hline 7 & 0.85 & 365 & 46062 & 497 & 0.378 & 3.22 & 0.117 \\
\hline 4 & 0.88 & 428 & 55614 & 558 & 0.513 & 2.69 & 0.191 \\
\hline 8 & 0.89 & 428 & 78397 & 552 & 0.502 & 2.69 & 0.187 \\
\hline
\end{tabular}

${ }^{a}$ In acetonitrile. 


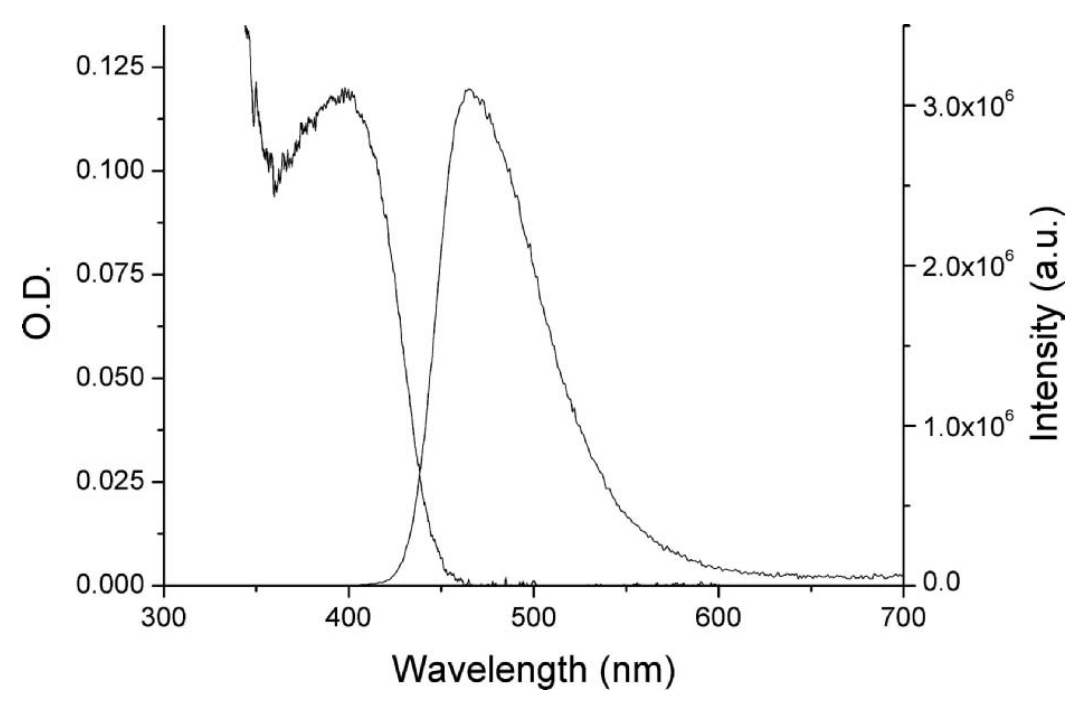

Fig. 2. Absorption (left, $\lambda_{\text {maximum }} 400 \mathrm{~nm}$ ) and fluorescence (right, $\lambda_{\text {maximum }} 465 \mathrm{~nm}$ ) spectra of compound $\mathbf{1}$ in toluene.

the fluorescence quantum yield in our study. For triarylamines, the compounds $\mathbf{1}-\mathbf{8}$ show relatively high fluorescence quantum yields $\left(\phi_{\mathrm{F}}\right.$, Table I), which are markedly affected by the substituents on the arylamine rings, with compounds 4 and 8 presenting the highest values. Since these compounds, having nitro groups, are likely to have the most polar-excited states of the compounds studied, it will be of considerable interest to study solvent effects on both absorption and fluorescence spectra. Studies are in progress on this. Further, the fact that the dehydroabietic acid moiety does not significantly affect the $\phi_{\mathrm{F}}$ values, while it does enhance solubility, means that it will be possible to study compound $\mathbf{4}$ in a wide range of solvents to test its potential as a polarity probe. The fluorescence lifetimes $\left(\tau_{\mathrm{F}}\right)$ and the fluorescence rate constants $\left(k_{\mathrm{F}}\right)$ are not significantly affected by the substituents on the arylamine rings and by the presence of the dehydroabietic acid moiety, suggesting that in this nonpolar solvent the substituents do not play any major part in the deactivation processes.

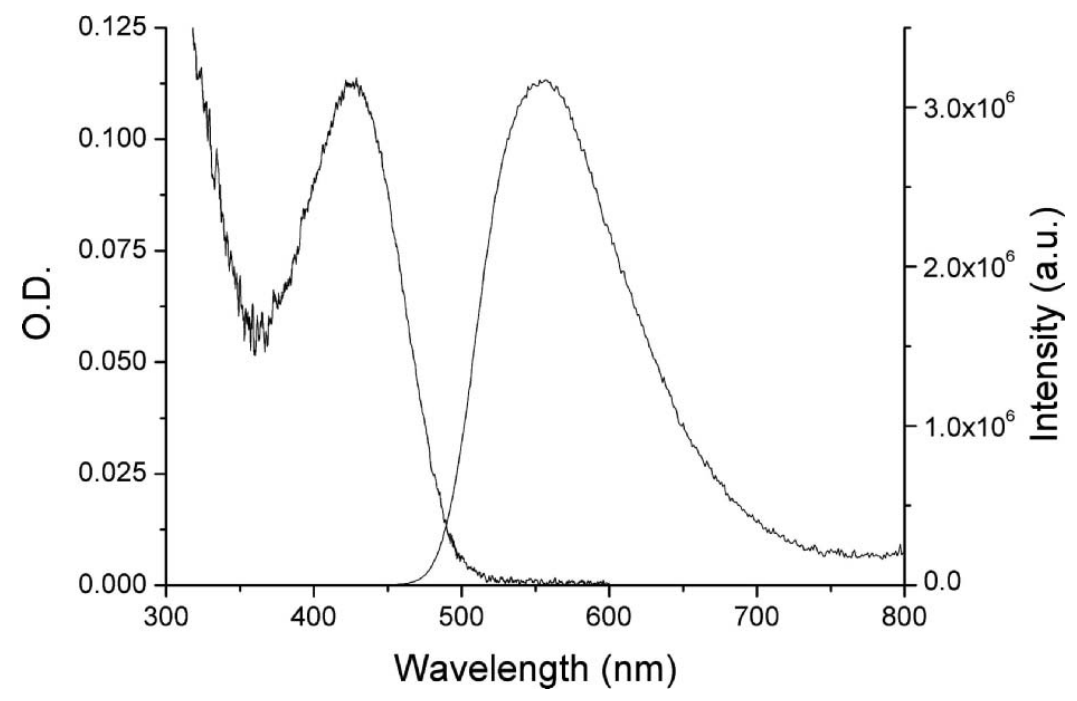

Fig. 3. Absorption (left, $\lambda$ maximum $428 \mathrm{~nm}$ ) and fluorescence (right, $\lambda$ maximum $558 \mathrm{~nm}$ ) spectra of compound $\mathbf{4}$ in toluene. 


\section{CONCLUSIONS}

The photophysical properties of a series of bipolar compounds containing quinoxaline and triarylamine groups have been studied. They show strong absorption bands and relatively high quantum yields of fluorescence. The emission maxima can be tuned over a wide range of wavelengths $(465-558 \mathrm{~nm})$ by changing substituents on the arylamine rings. Thus, the presence of dehydroabietic acid moieties to enhance solubility does not significantly affect their photophysical properties.

\section{ACKNOWLEDGMENTS}

We thank the Programa Operacional Ciência, Tecnologia, Investigação (POCTI), Fundação para a Ciência e a Tecnologia (FCT) and the Fundo Europeu de Desenvolvimento Regional (FEDER) for financial support. One of us (SMF) thanks FCT for the award of a Postdoctoral Fellowship.

\section{REFERENCES}

1. R. H. Friend, R. W. Gymer, A. B. Holmes, J. H. Burroughes, R. N. Marks, C. Taliani, D. D. C. Bradley, D. A. Dos Santos, J. L. Brédas, M. Löglund, and W. R. Salaneck (1999). Electroluminescence in conjugated polymers. Nature 397, 121-128.

2. S. R. Forrest (2004). The path to the ubiquitous and low-cost organic electronic appliances on plastic. Nature 428, 911-918.

3. D. M. Pai, J. F. Yanus, and M. Stolka (1984). Trap-controlled hopping transport. J. Phys. Chem. 88, 4714-4717.
4. K. R. Justin Tomas, J. T. Lin, Y.-T. Tao, and C.-H. Chuen (2002). Electroluminescent bipolar compounds containing quinoxaline or pyridopyrazine and triarylamine segments. J. Mater. Chem. 14, 3516-3522.

5. P. Karastatiris, J. A. Mikroyannidis, I. K. Spiliopoulos, A. P. Kulkarni, and S. A. Jenekhe (2004). Synthesis, photophysics, and electroluminescence of new quinoxaline-containing poly $(p$ phenylenevinylene)s. Macromolecules 37, 7867-7878.

6. T. Hirayama, S. Yamasaki, H. Ameku, T. Ishi-i, T. Thiemann, and S. Mataka (2005). Fluorescent solvatochromism of bipolar $\mathrm{N}, \mathrm{N}$-diphenylaminoaryl-substituted hexaazatriphenylenes, tetraazaphenanthrene, and quinoxalines. Dyes Pigments 67, 105-110.

7. H. D. Burrows, R. A. E. Castro, M. A. Esteves, B. Gigante, M. L. P. Leitão, and A. C. Pauleta (2006). Novel organic hole transport layers for molecular electronic systems. Mater. Sci. Forum 514-516, 8-12.

8. H. D. Burrows, R. A. E. Castro, M. A. Esteves, B. Gigante, J. Morgado, M. L. P. Leitão, and A. C. Pauleta (2006). Dehydroabietic acid based triarylamines as novel hole transport layer. J. Mater. Chem. submitted for publication.

9. J. E. Adams, W. W. Mantulin, and J. R. Huber (1973). Effect of molecular geometry on spin-orbit coupling of aromatic amines. $J$. Am. Chem. Soc. 95, 5477-5481.

10. T. Fonseca, B. Gigante, M. M. Marques, T. L. Gilchrist, and E. DeClercq (2004). Synthesis and antiviral evaluation of benzimidazoles, quinoxalines and indoles from dehydroabietic acid. Bioorg. Med. Chem. 12, 103-112.

11. T. Yamamoto, M. Nishiyama, and Y. Koie (1998). Palladiumcatalyzed synthesis of triarylamines from aryl halides and diarylamines. Tetrahedron Lett. 39, 2367-2370.

12. B. Gigante, M. A. Esteves, A. M. Guerreiro, S. M. Fonseca, and H. D. Burrows, Electroluminescent bipolar compounds based on dehydroabietic acid arylamine-quinoxalines, J. Mater. Chem., submitted for publication.

13. R. S. Becker, J. Seixas de Melo, A. L. Maçanita, and F. Elisei (1996). Comprehensive evaluation of the absorption, photophysical, energy transfer, structural, and theoretical properties of $\alpha$-oligothiophenes with one to seven rings. J. Phys. Chem. 100, 18683-18695.

14. G. Striker, V. Subramaniam, C. A. M. Seidel, and A. Volkmer (1999). Photochromicity and fluorescence lifetimes of green fluorescent protein. J. Phys. Chem. B 103, 8612-8617. 